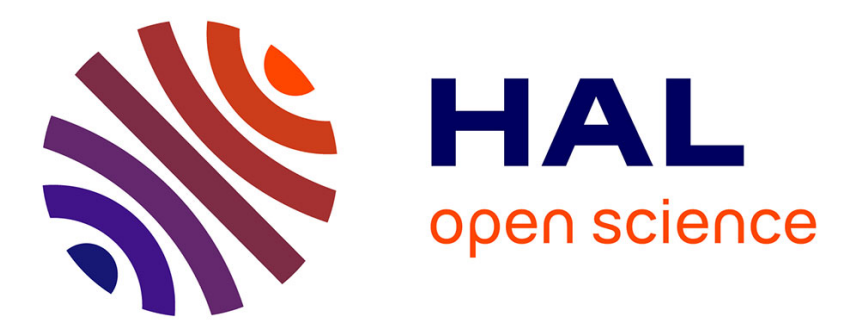

\title{
Molecular flexibility in nematic phases: direct determination of separate molecular core and alkyl tail rotational relaxation times
}

\author{
M.P. Fontana, N. Kirov
}

\section{- To cite this version:}

M.P. Fontana, N. Kirov. Molecular flexibility in nematic phases: direct determination of separate molecular core and alkyl tail rotational relaxation times. Journal de Physique Lettres, 1985, 46 (7), pp.341-345. 10.1051/jphyslet:01985004607034100 . jpa-00232521

HAL Id: jpa-00232521

https://hal.science/jpa-00232521

Submitted on 1 Jan 1985

HAL is a multi-disciplinary open access archive for the deposit and dissemination of scientific research documents, whether they are published or not. The documents may come from teaching and research institutions in France or abroad, or from public or private research centers.
L'archive ouverte pluridisciplinaire HAL, est destinée au dépôt et à la diffusion de documents scientifiques de niveau recherche, publiés ou non, émanant des établissements d'enseignement et de recherche français ou étrangers, des laboratoires publics ou privés. 
Classification

Physics Abstracts

$61.30-33.20 \mathrm{~B}$

\title{
Molecular flexibility in nematic phases : direct determination of separate molecular core and alkyl tail rotational relaxation times
}

\author{
M. P. Fontana \\ Dipartimento di Fisica and GNSM-CISM, University of Parma, Italy \\ and N. Kirov \\ Institute of Solid State Physics, 72, boul. Lenin, Sofia 1184, Bulgaria
}

(Reçu le 12 novembre 1984, révisé le 28 janvier 1985, accepté le 31 janvier 1985)

\begin{abstract}
Résumé. - Dans cette Lettre nous reportons la première détermination directe de deux temps de relaxation rotationnelle, le premier étant corrélé avec le noyau moléculaire, le deuxième avec la chaîne alkyl terminale, pour plusieurs molécules mésomorphes en phase nématique. Nous avons achevé cette détermination par l'analyse de Fourier des bandes d'absorption infrarouge dues aux vibrations des groupes moléculaires dans le noyau et la chaîne terminale respectivement.

Abstract. - In this Letter we report the first direct determination of two separate rotational relaxation times, one connected with the molecular core, the other with the alkyl tail, of several mesomorphic molecules in their nematic phase. The determination was achieved by Fourier transform analysis of IR absorption bands connected with molecular vibrations in the core and in the tail regions respectively.
\end{abstract}

The rod-shaped liquid crystalline molecules are usually considered as rigid and their spinning motion about the long molecular axis is characterized by a single relaxation time. However there is evidence from neutron scattering [1-3], NMR [4] and dielectric [5] data that the alkyl tails (mesogens usually have long paraffin chains attached to one or both sides of a central molecular core) rotate faster than the core, i.e. the oxygen, nitrogen or other heteroatoms attached to the benzene rings, the bridge between the rings and the rings themselves. Furthermore it appears that some residual rotational tail motion persists in the solid phase of the mesogens. This fact is also confirmed by calorimetric data [6]. However, perhaps due to the limited number of experimental data available, and to the uncertainties in their interpretation connected with the use of intermediary modelling, no quantitative determinations of the reorientational correlation times of the paraffin chains of mesomorphic molecules are available in the literature so far.

Recently we have demonstrated the applicability of Fourier analysis of infrared absorption bands in ordered fluids to the determination of reorientational correlation times and diffusion 
coefficients [7]. The basic feature of our method is the exploitation of the dichroism arising from the establishment of an orientationally ordered phase, such as a nematic one, in a molecular fluid. By taking the ratio of the Fourier transforms of the absorption bands for light polarized parallel and perpendicular to the nematic axis respectively, the vibrational contribution to the IR band broadening (and also other effects, such as local field corrections and instrumental resolution) is divided out, directly yielding the orientational correlation function connected with those rotational fluctuations of the molecules which broaden the specific vibrational band under study. Thus for aligned nematics the problem of having to estimate the vibrational contribution to the IR bandshape in order to subtract it out is automatically solved, and IR spectroscopy becomes equivalent to the more traditionally used technique of polarized Raman spectroscopy [8]. When applicable, IR spectroscopy, being connected with the time modulation of a vector quantity (e.g. a dipole moment), has the advantage over Raman spectroscopy (connected instead with the time modulation of the polarizability - a tensor quantity), of a simpler and more direct connection between the spectra and the geometry of the vibrational modes. Thus it is easier to choose the vibrational mode of a particular group which will be most sensitive to a given type of rotation (for instance, the spinning motion about the major molecular axis).

In any case, the band shape analysis of vibrational modes assigned to different and specific molecular segments will yield direct and quantitative information on the reorientational dynamics of different molecular groups, and thus determine separately $\tau_{\text {core }}^{\text {s }}$ (the core spinning relaxation time) and $\tau_{\text {tail }}^{\text {s }}$ (the tail spinning relaxation time). The determination of the perpendicular (tumbling) relaxation times is more difficult and less precise with infrared spectroscopy, and thus we shall not consider it further.

In this Letter we report the determination of $\tau_{\text {core }}^{\mathrm{s}}$ and $\tau_{\text {tail }}^{\mathrm{s}}$ by Fourier analysis of selected IR absorption bands of three aligned nematic liquid crystals, namely $\mathrm{N}$-(4-ethoxybenzylidene) 4', n-butylaniline (EBBA), 4, n-pentyl 4'-methoxytolane (PMT) and 4, n-hexyl ester of 4, n-butyloxyazoxybenzoic acid (BABAHE). The temperature range of their nematic phases are : $310-350 \mathrm{~K}$ (EBBA); 314-326 K (PMT); 300-350 K (BABAHE). The basic experimental set-up (spectrometer, sample cell, temperature control, sample alignment procedures, Fourier transform procedures) is described in reference [7]. The orientational order parameter $\left\langle P_{2}\right\rangle$ is determined using the strongly longitudinally polarized benzene ring stretch vibration in the region $1605-1595 \mathrm{~cm}^{-1}$ (1 $598 \mathrm{~cm}^{-1}$ - EBBA, $1600 \mathrm{~cm}^{-1}$ - PMT and $1603 \mathrm{~cm}^{-1}$ - BABAHE) according to the equation [9] :

$$
\left\langle P_{2}\right\rangle=\frac{R-1}{R+2}
$$

where the dichroic ratio $R=A_{\|} / A_{\perp}, A_{\|}, A_{\perp}$ being the absorption coefficients for light polarized parallel and perpendicular to the nematic axis respectively. $\left\langle P_{2}\right\rangle$ for the investigated mesomorphic materials is found to be : EBBA - 0.52(312 K), PMT - 0.60(316 K) and BABAHE $0.56(320 \mathrm{~K})$; these values are within the normal limits for the nematic phase [10].

The following IR bands have been selected : $\mathrm{CH}_{2}$ rocking of the paraffin chain at $724 \mathrm{~cm}^{-1}$ for all investigated compounds. O-C stretch at $1047 \mathrm{~cm}^{-1}$ (EBBA), C-H aromatic out-of-plane deformation " Umbrella » at $833 \mathrm{~cm}^{-1}(\mathrm{PMT})$ and $837 \mathrm{~cm}^{-1}$ (BABAHE), benzene ring in-plane deformation at $1115 \mathrm{~cm}^{-1}$ (EBBA) and benzene out-of-plane deformation at $535 \mathrm{~cm}^{-1}$ (BABAHE) (Fig. 1). All bands are weakly polarized ( $R$ is between 0.4 and 1.8), moderately intense and well separated from the other peaks. For all investigated modes the angle between the vibrational transition dipole moment and the long molecular axis is between $45^{\circ}$ and $60^{\circ}$. Thus the rotational contribution will be about $10-20 \%$ of the total band shape [7]. The strongly longitudinally polarized modes of the mesomorphic molecules are usually totally dominated by the vibrational relaxation and thus cannot be used to study the spinning motion. The shape of the lines $-1047 \mathrm{~cm}^{-1}, 833 \mathrm{~cm}^{-1}, 837 \mathrm{~cm}^{-1}$ and $535 \mathrm{~cm}^{-1}$ is close to Lorentzian while the bands 


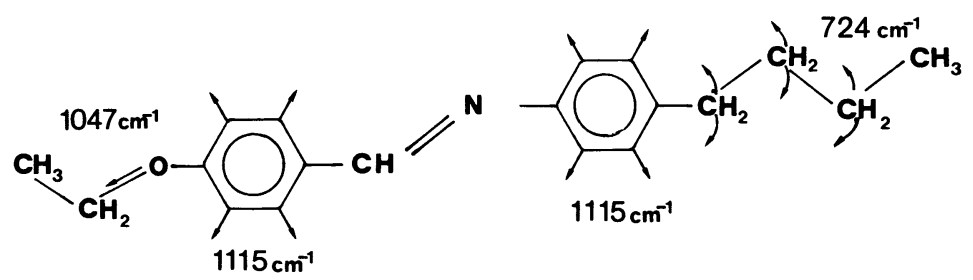

Fig. 1. - The EBBA molecule. In the figure we indicate the location on the molecule of the molecular groups whose vibrational modes we used in determining the rotational correlation times.

$724 \mathrm{~cm}^{-1}$ and $1115 \mathrm{~cm}^{-1}$ are asymmetric due to additional components : thus numerical curve resolving and best fit procedures have been applied in order to extract the Lorentzian shape of these vibrations. The transition dipole moment vector of the bands assigned to the benzene ring vibrations can rotate by the rotation of the molecules around their long axis. Thus, the band shape analysis of these modes will give the correlation times for the rotation of the molecular core $\tau_{\text {core }}^{\mathrm{s}}$. The $\mathrm{CH}_{2}$ rocking depends on the paraffin chain reorientation around the symmetry molecular axis, and therefore will give the relaxation times of the alkyl tail $\tau_{\text {tail }}^{\mathrm{s}}$.

The rotational contribution is obtained from the total band shape using the method proposed in [7]. The Fourier transformation is done by direct numerical integration at each time point. To increase the accuracy the Fourier inversion was averaged over five spectral recordings of each band. The studied bands are truncated at five times the full width at half maximum (FWHM). We could not extend the spectral range further since the spectra of the mesomorphic materials in general (and of ours in particular) are very complicated and consist of many bands relatively close to each other. All measurements were carried out at temperatures two degrees above the crystal-nematic phase transition. Figure 2 displays the normalized correlation functions $C_{1 \mathrm{R}}(t)$

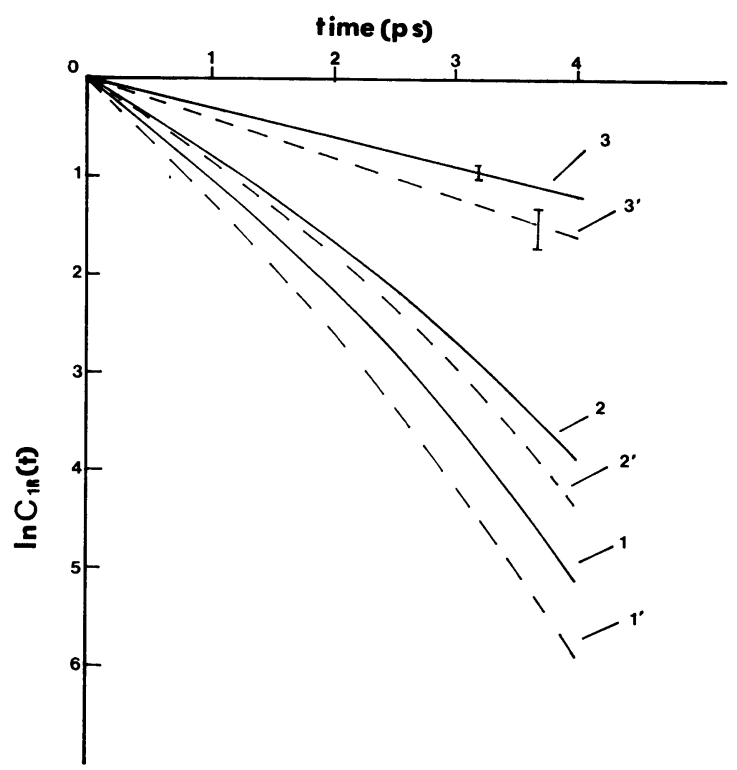

Fig. 2. - Dipole correlation functions of the bands $1047 \mathrm{~cm}^{-1}$ (full line) and $724 \mathrm{~cm}^{-1}$ (dashed line) from the IR spectrum of EBBA at $312 \mathrm{~K} ; 1,1^{\prime}-E \perp n$ (rotational + vibrational relaxation parts); 2, 2' $-E \| n$ (vibrational relaxation part); $3,3^{\prime}-$ rotational contribution to the total band shape. 
for the bands $1047 \mathrm{~cm}^{-1}$ and $724 \mathrm{~cm}^{-1}$ from the IR spectrum of EBBA as well as the rotational correlation functions. Similar results when obtained for the other mesogens. The rotational correlation time is determined as the inverse slope of the plot $\ln C_{1 \mathrm{R}}(t)$ versus time using least square and linear regression fit procedures. The results averaged over five independent measu,rements of each band are summarized in table I. These data prove quantitatively that a faster

Table I. - Molecular core $\tau_{\text {core }}^{\mathrm{s}}$ and alkyl tail $\tau_{\text {tail }}^{\mathrm{s}}$ rotational relaxation times.

\begin{tabular}{|c|c|c|c|}
\hline $\begin{array}{c}\text { relaxation } \\
\text { time }(\mathrm{ps})\end{array}$ & \multicolumn{1}{|c|}{$\begin{array}{c}\text { EBBA } \\
(312 \mathrm{~K})\end{array}$} & $\begin{array}{c}\text { PMT } \\
(316 \mathrm{~K})\end{array}$ & $\begin{array}{c}\text { BABAHE } \\
(302 \mathrm{~K})\end{array}$ \\
\hline & $3.5\left(^{+}\right)\left(1047 \mathrm{~cm}^{-1}\right)$ & & \\
$\tau_{\text {core }}^{\mathrm{s}}$ & $3.8\left(^{++}\right)\left(1115 \mathrm{~cm}^{-1}\right)$ & $3.6\left(^{+}\right)\left(833 \mathrm{~cm}^{-1}\right)$ & $3.8\left(^{+}\right)\left(535 \mathrm{~cm}^{-1}\right)$ \\
$\tau_{\text {tail }}^{\mathrm{s}}$ & $2.6\left(^{++}\right)\left(724 \mathrm{~cm}^{-1}\right)$ & $2.4\left(^{++}\right)\left(724 \mathrm{~cm}^{-1}\right)$ & $2.7\left(^{++}\right)\left(724 \mathrm{~cm}^{-1}\right)$ \\
\hline
\end{tabular}

$\left({ }^{+}\right)$mean error about $4 \%$. (Estimated from fitting precision.)

$\left({ }^{++}\right)$mean error about $10-12 \%$. This higher error arises from the curve resolving and best fit procedures.

reorientational motion of the alkyl tails of the liquid crystalline molecules presumably with larger amplitude displacement and big giration radius is superimposed on the rotation of the molecular core. $\tau_{\text {tail }}^{\text {s }}$ might be temperature and phase dependent and this dependence will be the subject of further investigations.

In conclusion, we have demonstrated directly and quantitatively that mesogenic molecules in the nematic phase are flexible, and in particular that the core and tail rotation are somewhat decoupled. However, the corresponding relaxation times are not too different, as had been conjectured [2]; this might imply that although the mesogenic molecule is not rigid, the constraints under which its segments are forced to move make the reorientational dynamics for them very similar. In this sense our results leave open some of the problems posed by the discrepancy between neutron scattering (and our) results and those of dielectric measurements [5].

\section{Acknowledgments.}

We wish to thank Prof. J. A. Janik for helpful discussions. This work is a part of the collaboration program between the Physics Department at the University of Parma and the Institute of Solid State Physics at the Bulgarian Academy of Sciences.

One of us (N.K.) thanks the University of Parma for the financial support and its hospitality.

\section{References}

[1] Hervet, H., Volino, F., Dianoux, A. J. and Lecher, R. E., J. Physique Lett. 35 (1974) L-151.

[2] JaniK, J. A., KrawCZyK, J., JaniK, J. M. and Otnes, K., J. Physique Colloq. 40 (1979) C3-169.

[3] JANiK, J. A., JANIK, J. M., OtNes, K., KrawCZYK, J. and Rosciszewski, K., Physica B 92 (1977) 351.

[4] WöLfEl, W., NoACK, F. and Strohrer, M., Z. Naturforsch. a 30 (1975) 437.

[5] Maurel, P. and Price, A. H., J. Chem. Soc. Faraday Trans. II 69 (1973) 1486.

The dielectric data however yield relaxation times which are one order of magnitude longer than those obtained by quasi-elastic neutron scattering and also those reported in this work. 
[6] Andrews, J. T. S., Phys. Lett. A 46 (1974) 377.

[7] Dozov, I., Kirov, N. and Fontana, M. P., J. Chem. Phys. 81 (1984) 2585.

[8] Clarke, J. H. R., in Advances of IR and Raman Spectroscopy, R. J. H. Clark and R. E. Hester, Eds. (Heyden) vol. 4, 1977.

[9] NeFF, V. D., in Liquid Crystals and Ordered Fluids, J. F. Johnson and R. S. Porter, Eds. (Plenum Press) vol. 2, 1974.

[10] Priestley, E. B., RCA Review 35 (1974) 144. 